\title{
FAKTOR PENYEBAB ANAK PUTUS SEKOLAH
}

\author{
Abdul Hakim \\ BPS Provinsi Aceh \\ e-mail: \\ ahakim@bps.go.id
}

\begin{abstract}
Abstrak: Pembangunan di bidang pendidikan merupakan suatu hal yang sangat penting dalamm eningkatkan kualitas Sumber Daya Manusia. Oleh karena itu, pemerintah menetapkan program wajib belajar 12 tahun agar tercipta SDM yang berkualitas. Namun, partisipasi sekolah pada tingkat sekolah menengah perlu ditingkatkan agar angka putus sekolah dapat ditekan. Penelitian ini dilaksanakan di Provinsi Aceh menggunakan data Susenas Maret 2019 dengan tujuan mengidentifikasi variabel yang mempengaruhi angka putus sekolah pada usia 7-18 tahun. Selain itu, dapat juga untuk mengetahui probabilitas anak putus sekolah dengan karakteristik tertentu. Analisis yang digunakan adalah regresi logistik, yaitu suatu metode yang menerangkan hubungan antara variabel respon dikotomi dan satu set variabel penjelas katagori. Enam variabel yang dipilih mampu menjelaskan variasi anak putus sekolah dengan tingkat signifikan $5 \%$. Variabel tersebut adalah pendidikan kepala rumah tangga, kepemilikan KIP/PIP, jumlah anggota rumah tangga, anak yang bekerja, kemiskinan, dan daerah tempat tinggal. Variabel yang paling dominan adalah kepemilikan KIP/PIP.
\end{abstract}

Kata kunci: putus sekolah, pendidikan, wajib belajar, regresi logistik

\section{FACTORS AFFECTING STUDENTS DROPOUTS}

Abstract: To improve the quality of human resources, the development of the education sector is very important.. Therefore, the Indonesian government has established a 12-year compulsory education program to create quality human resources. However, education participation at the secondary level needs to be increased, and the dropout rate needs to be controlled. This study uses secondary data from the March 2019 National SocioEconomic Survey (Susenas) to identify variables that affect the dropout rate for students ages 7 to 18 years in Aceh. In addition, the purpose of this study is to determine the probability of school dropouts by certain characteristics. The analysis used is logistic regression, which is a method that explains the relationship between the dichotomous response variable and a set of categorical explanatory variables. The result shows that the six variables selected were able to explain the variation of dropouts with a significance level of 5 percent. These variables are the education of household head, Kartu Indonesia Pintar/Program Indonesia Pintar (KIP/PIP) ownership, household size, working children, poverty, and urban-rural classification. The most dominant independent variable is ownership of KIP/PIP.

Keywords: school dropout, education, compulsory education, logistic regression 


\section{PENDAHULUAN}

Setiap negara pasti akan memperhatikan pembangunan dibidang pendidikan, karena untuk mencetak dan meningkatkan SDM yang cerdas dan terampil di perlukan pendidikan yang baik. Pendidikan yang diberikan saat ini, akan menentukan kecerdasan dan kemampuan suatu bangsa di masa depan. Pendidikan sangat memegang peranan penting dalam proses pembentukan SDM berkualitas yang memiliki daya saing tinggi dan dapat menyerap perkembangan teknologi, sehingga mampu meningkatkan produktivitas. Hal ini berarti, kondisi pendidikan di suatu wilayah dapat mencerminkan kualitas SDM-nya yang secara umum akan mendukung percepatan pembangunan (Wassahua, 2016). Dengan demikian dapat dikatakan bahwa pendidikan sangat memegang peranan penting dalam meningkatkan kualitas SDM. Oleh karena itu, sejak tahun 1994 pemerintah telah penerapkan program wajib belajar pendidikan dasar 9 tahun dengan harapan semakin baik tingkat pendidikan akan semakin baik pula tingkat kesejahteraan. Selanjutnya program wajib belajar ditambah menjadi 12 tahun, hal ini seiring dengan perkembangan teknologi yang menuntut pendidikan dan keterampilan yang semakin tinggi. Sejak tahun 2010 program wajib belajar mengalami perubahan menjadi hak belajar, karena setiap warga negara mempunyai hak yang sama untuk memperoleh pendidikan yang bermutu, sesuai dengan yang diamanatkan UU No. 20 Tahun 2003 tentang Sistem Pendidikan Nasional.

Pada Renstra Kemendikbud 2020-2024 disebutkan bahwa, secara garis besar arah kebijakan Kementerian Pendidikan dan Kebudayaan (Kemendikbud) salah satunya adalah optimalisasi angka partisipasi pendidikan. Kondisi yang ingin dicapai dalam peningkatan angka partisipasi pendidikan adalah: (1) Angka partisipasi pendidikan anak usia dini meningkat; (2) Wajib belajar sembilan tahun tuntas dan wajib belajar duabelas tahun meningkat; dan (3) Angka partisipasi pendidikan tinggi meningkat. Terkait dengan program wajib belajar dua belas tahun, pemerintah telah menyusun beberapa strategi yang tertuang dalam Restra tersebut, salah satu diantaranya adalah dengan memenuhi kebutuhan daya tampung untuk semua jenjang pendidikan melalui pembangunan sekolah dan rehabilitasi fasilitas yang rusak. Hal tersebut untuk menjamin akses pendidikan yang mudah dan murah.

Pengertian dari Angka Partisipasi Sekolah menurut BPS (www.bps.go.id) adalah rasio anak yang sekolah pada kelompok umur tertentu terhadap jumlah penduduk pada kelompok umur yang sama. Sedangkan bersekolah adalah mereka yang terdaftar dan aktif mengikuti pendidikan baik di suatu jenjang pendidikan formal (pendidikan dasar yaitu SD/sederajat dan SMP/sederajat, pendidikan menengah yaitu SMA/sederajat dan pendidikan tinggi yaitu PT/sederajat) maupun non formal (Paket A setara SD, paket B setara SMP dan paket C setara SMA) yang berada di bawah pengawasan Kementerian Pendidikan Nasional (Kemdiknas), Kementerian Agama (Kemenag), dan instansi lainnya negeri maupun swasta.

Partisipasi sekolah berbanding terbalik dengan putus sekolah. Angka putus sekolah menggambarkan tingkat putus sekolah pada suatu jenjang pendidikan dan merupakan proporsi anak usia sekolah yang sudah tidak sekolah lagi atau tidak menamatkan suatu jenjang pendidikan tertentu. Fenomena putus sekolah ini dapat disebabkan oleh beberapa faktor, antara lain kurangnya kesadaran orang tua akan pentingnya pendidikan anak, keterbatasan ekonomi, keadaan geografis yang kurang 
menguntungkan, keterbatasan akses menuju ke sekolah, jarak sekolah yang jauh atau minimnya fasilitas pendidikan di suatu daerah (BPS, 2019). Terkait dengan keterbatasan akses dan fasilitas sekolah biasanya dapat tergambar dari daerah perkotaan atau daerah perdesaan.

Ada tiga kelompok usia sekolah yang menjadi perhatian dalam program wajib belajar dua belas tahun sesuai dengan jenjang pendidikan, yaitu kelompok usia 7-12, 13-15, dan 16-18 tahun. Perkembangan angka partisipasi sekolah (APS) di Indonesia untuk kelompok usia 7-12 dan 13-15 tahun cukup baik, namun untuk kelompok usia 16-18 tahun masih perlu ditingkatkan. Berdasarkan data BPS (www.bps.go.id), APS untuk kelompok usia 7-12 dan 13-15 tahun sudah mencapai lebih dari 95 persen, sedangkan untuk kelompok usia 16-18 tahun masih dibawah 75 persen. Selama periode 3 tahun terakhir, terjadi peningkatan APS 16-18 tahun yaitu 71,42 persen pada tahun 2017 meningkat menjadi 71,99 persen pada tahun 2018 kemudian meningkat lagi pada tahun 2019 menjadi 72,36 persen.

Berdasarkan penjelasan di atas, angka putus sekolah khususnya untuk kelompok 16-18 tahun masih relatif tinggi, permasalahan tersebut yang menjadi perhatian pada penelitian ini. Tujuan utama penelitian ini adalah untuk mengidentifikasi variabel yang mempengaruhi angka putus sekolah pada usia 7-18 tahun menggunakan analisis regresi logistik. Menurut Irwan Gani dan Siti Amalia (2015), regresi logistik adalah salah satu bentuk model regresi nonlinier yang menggunakan fungsi eksponensial dalam pendugaan parameternya. Variabel dependen menggunakan data kategorik dan variabel independen bisa benbentuk numerik dan/atau kategorik.

Penelitian terkait anak putus sekolah telah banyak dilakukan. Berdasarkan penelusuran penulis, sebagian besar penelitian tersebut dilakukan pada tingkat pendidikan dasar, menggunakan data kualitatif, dan merupakan studi kasus level desa atau kecamatan dengan jumlah sampel ralitif sedikit. Penulis juga belum penemukan penelitian terkait anak putus sekolah pada level Provinsi Aceh. Kondisi ini yang mendorong penelitian tentang anak putus sekolah pada tingkat pendidikan dasar dan menengah, menggunakan data kuantitatif, dengan cakupan level provinsi dari sampel yang memenuhi kaidah sampling.

Menurut Cahyani et al. (2019) anak putus sekolah adalah seseorang yang telah meninggalkan sekolah sebelum menyelesaikan studinya atau dapat juga dikatakan anak usia sekolah yang tidak sekolah lagi dan tidak memperoleh ijazah. Faktor-faktor yang yang mempengaruhi anak putus sekolah addalah kurangnya minat dan kemauan untuk bersekolah, siswa tidak tertarik untuk sekolah, ketidakmampuan mengikuti/mengambil pelajaran, ekonomi keluarga, orang tuan kurang perhatian, dan lingkungan bermain anak-anak. Hasil analisis faktor yang menunjukkan bahwa faktor yang paling dominan mempengaruhi anak putus sekolah di tingkat SMP adalah kurangnya perhatian orang tua, sedangkan untuk tingkat menengah adalah anak kurang berminat dan kemauan untuk sekolah.

Saepuloh \& Suherman, (2018) dalam penelitiannya mengatakan bahwa penyebab angka putus sekolah di Kota tangerang adalah: (1) Keadaan ekonomi masyarakat lemah; (2) Dukungan dari dari orang tua dan lingkungan tempat tinggal masih kurang; (3) Program pendidikan dari pemerintah terbatas, sehingga belum mampu menjangkau seluruh masyarakat yang kurang mampu. 
Selanjutnya penelitian yang dilakukan di Kota Yogyakarta, yang bertujuan untuk mengevaluasi pelaksanaan program, pencapaian tujuan program, dan hambatan-hambatan pelaksanaan program wajib belajar 12 tahun di Kota Yogyakarta. Penelitian ini merupakan penelitian evaluasi dengan menggunakan pendekatan kualitatif. Model evaluasi yang digunakan adalah discrepancy evaluation program, yaitu untuk mengetahui ketidaksesuaian antara standar yang telah ditetapkan dalam program dengan pelaksanaan program itu sendiri. Hasil penelitian tersebut menunjukkan bahwa ada beberapa hal yang menghambat program wajib belajar dua belas tahun yaitu: (1) Tanaga pendidik belum terpenuhi pada jenjang SD; (2) Sarana prasarana belum terpenuhi; (3) Rendahnya daya beli/tingkat partisipasi masyarakat terhadap pembiayaan pendidikan; (4) Kesadaran orang tua dan minat anak masih rendah terhadap pentingnya pendidikan; dan (5) Tidak tepatnya subsidi pemerintah Kota Yogyakarta (Hasanah, Safruddin, Jabar, Pauh, \& Singingi, 2017).

(Astari et al., 2013) dalam penelitiannya mengatakan bahwa variabel yang mempengaruhi anak putus sekolah pada pendidikan dasar adalah adalah rasio siswa terhadap sekolah pada tiap kecamatan, rasio siswa terhadap guru pada tiap kecamatan, jumlah kepala keluarga dengan pendidikan terakhir ayah SD atau SMP, angka buta huruf, dan rata-rata jumlah anggota keluarga. Rasio siswa terhadap guru pada tiap kecamatan merupakan variabel yang memiliki pengaruh paling besar dibandingkan dengan keempat variabel signifikan yang lainnya.

\section{METODE}

Penelitian ini dilakukan di Provinsi Aceh menggunakan data hasil Survei Sosial Ekonomi Nasional (Susenas) Maret 2019 yang dilaksanakan BPS. Sasaran penelitian adalah anak usia sekolah dasar dan menengah (7-18 tahun). Dari sampel Susenas yang tersebar di seluruh Aceh tersebut, diperoleh sejumlah 11.463 anak usia 7-18 tahun yang menjadi unit penelitian. Alat analisis yang digunakan adalah regresi logistik, dimana regresi ini untuk melihat hubungan antar variabel dependen $(Y)$ dan beberapa variabel independen $(X i)$. Menurut Irwan Gani dan Siti Amalia (2015), regresi logistik adalah salah satu bentuk model regresi nonlinier yang menggunakan fungsi eksponensial dalam pendugaan parameternya. Variabel dependen menggunakan data kategorik dan variabel independen bisa benbentuk numerik dan/atau kategorik. Model parameter dapat diduga dengan menggunkan metode maksimum likelihood, yaitu suatu prosedur pencarian satu atau lebih parameter yang secara statistik memberikan distribusi atau kemungkinan terbesar dari suatu paramater $\theta$.

Variabel-variable yang menjadi objek penelitian adalah anak usia sekolah (7-18 tahun) sebagai variabel dependen dan enam variabel yang mempengaruhinya (variabel Independen). Definisi variabel operasional tersebut adalah sebagai berikut:

1. Variabel tak bebas adalah anak usia sekolah (Y), dengan

kategori

- $\quad$ putus sekolah $=1$

- $\quad$ tidak putus sekolah $=0$. 
2. Variabel bebas

a. Pendidikan kepala rumah tangga $\left(X_{1}=e d u\right)$, dengan kategori

- $\quad$ tamat SMP ke bawah = 1

- $\quad$ tamat SMA ke atas $=0$

b. Kepemilikan Kartu Indonesia Pintar/Program Indonesia Pintar $(\mathrm{KIP} / \mathrm{PIP})\left(X_{2}=\right.$ smart $)$, dengan kategori

- $\quad$ idak memiliki KIP/PIP = 1

- memiliki KIP/PIP = 0 .

C. Jumlah anggota rumah tangga $\left(X_{3}=h s\right)$, dengan kategori

- 6 orang atau lebih = 1

- 5 orang atau kurang $=0$.

d. Aktivitas bekerja $\left(X_{4}=\right.$ work $)$, dengan kategori

- tidak bekerja $=1$

- bekerja $=0$.

e. Kemiskinan $\left(X_{5}=\right.$ pov), dengan kategori

- $\operatorname{miskin}=1$

- $\quad$ tidak miskin $=0$

f. Daerah tempat tinggal $\left(X_{6}=\right.$ city $)$, dengan kategori

- $\quad$ perdesa $=1$

- $\operatorname{perkotaan}=0$.

Menurut Nachrowi dan Usman (2002), bentuk model regresi logirtik adalah:

$$
f(x)=\frac{e^{\beta_{0}+\beta_{1} X_{1}+\beta_{2} X_{2}+\ldots+\beta_{p} X_{p}}}{1+e^{\beta_{0}+\beta_{1} X_{1}+\beta_{2} X_{2}+\ldots+\beta_{p} X_{p}}}
$$

Adapun metode pengujian model dan parameter yang digunakan adalah statistik uji $G$ yaitu untuk uji secara simultan atau uji semua variabel penjelas dalam model secara bersama.

Selanjutnya interpretasi koefisien-koefisien dalam model regresi logistik dapat dilakukan dengan dua cara yaitu:

1. Odds ratio (perbandingan resiko) didefinisikan sebagai : $\frac{p}{1-p}$ (resiko)= $\exp \left(\beta_{i}\right)$

dimana $p$ menyatakan probabilitas sukses (terjadinya peristiwa $y=1$ ).

2. Adjusted probability (probabilita terjadi)merupakan probabilitas terjadinya suatu peristiwa $y=1$ dengan karakteristik yang telah diketahui, ditulis sebagai:

$$
P(y=1 \mid x)=f(x)=\frac{e^{\beta_{0}+\beta_{1} X_{1}+\beta_{2} X_{2}+\ldots+\beta_{p} X_{p}}}{1+e^{\beta_{0}+\beta_{1} X_{1}+\beta_{2} X_{2}+\ldots+\beta_{p} X_{p}}}
$$




\section{HASIL DAN PEMBAHASAN}

Tabel 1. Karakteristik Sampel

\begin{tabular}{|c|c|c|c|}
\hline \multicolumn{2}{|c|}{ Uraian } & \multirow{2}{*}{$\begin{array}{r}\text { Persentase } \\
53,28\end{array}$} & \multirow{2}{*}{$\begin{array}{r}\text { Jumlah } \\
6.289\end{array}$} \\
\hline \multirow{3}{*}{ Kelompok Umur } & $7-12$ & & \\
\hline & $13-15$ & 23,47 & 2.652 \\
\hline & $16-18$ & 23,25 & 2.522 \\
\hline \multirow{2}{*}{ ljazah krt } & SMA ke atas & 34,14 & 4.136 \\
\hline & SMP ke bawah & 65,86 & 7.327 \\
\hline \multirow{2}{*}{ Kepemilikan KIP/PIP } & Ada KIP/PIP & 34,40 & 3.540 \\
\hline & Tidak & 65,60 & 7.923 \\
\hline \multirow{2}{*}{ Bekerja*) } & Bekerja & 3,91 & 275 \\
\hline & Tidak & 96,09 & 7.802 \\
\hline \multirow{2}{*}{ Miskin } & Tidak & 79,36 & 9.690 \\
\hline & Miskin & 20,64 & 1.773 \\
\hline \multirow{2}{*}{ Kota/Desa } & Perkotaan & 31,45 & 3.293 \\
\hline & Perdesaan & 68,55 & 8.170 \\
\hline \multicolumn{2}{|c|}{ Total Sampel (anak) } & \multicolumn{2}{|c|}{11.463} \\
\hline \multicolumn{2}{|c|}{ Rata-rata Umur (tahun) } & \multicolumn{2}{|c|}{12,21} \\
\hline \multicolumn{2}{|c|}{ Rata-rata jumlah art (orang) } & \multicolumn{2}{|c|}{5,08} \\
\hline
\end{tabular}

Pada Tabel 1 disajikan karakteristik sampel anak usia sekolah 7-18 tahun. Total sampel sebesar 11.463 anak, dengan rincian 6.289 berumur 7-12 tahun, 2.652 berumur 13-15 tahun,dan yang berumur 16-18 tahun sebanyak 2.522 . Sampel tersebut didominasi anak usia 7-12 tahun. Rata-rata umur mereka adalah 12,21 tahun yang berarti berada pada usia anak Sekolah Dasar. Mereka tinggal di rumah tangga dengan rata-rata jumlah anggota rumah tangga 5,08 orang.

Sebagian besar kepala rumah tangga berijazah SMP ke bawah. Hal ini menggambarkan bahwa pendidikan dasar masih mendominasi tingkat pendid ikan orang tua yang bertanggungjawab atas anak dalam suatu rumah tangga, sehingga perhatian kepada anak menjadi penting untuk meningkatkan partisipasi sekolah. Kartu Indonesia Pintar/Program Indonesia Pintar (KIP/PIP) sangat memegang peranan penting dalam membantu masyarakat untuk bersekolah. Tabel 1 memperlihatkan bahwa sebagian besar anak usia sekolah tidak/belum memiliki atau mendapatkan KIP/PIP.

Aktivitas anak usia sekolah seharusnya lebih banyak pada kegiatan belajar dan kegiatan lain yang mendukung, bukan mencari atau membantu mencari nafkah. Aktivitas anak yang terkena sampel dalam penelitian ini sebagian besar tidak bekerja. Keadaan miskin suatu rumah tangga bukan menjadi tanggung jawab anak, akan tetapi keadaan miskin menjadi beban anak untuk melanjutkan sekolah 
yang lebih tinggi. Pada Tabel 1 terlihat sebagian besar mereka tinggal di rumah tangga yang tidak miskin. Kemajuan suatu daerah atau wilayah dapat memudahkan kita untuk mengakses fasilitas pelayanan dasar termasuk fasilitas sekolah, biasanya daerah perkotaan lebih lengakap fasilitas pelayanan dan mudah untuk mengaksesnya. Rumah tangga sampel ini lebih banyak yang tinggal di daerah perdesaan.

Berikutnya adalah hasil pengolahan data terkait dengan analisis regesi logistik. Aplikasi pengolahan data yang digunakan SPSS.

Tabel 2. Omnibus Tests of Model Coefficients

\begin{tabular}{ccccc}
\hline & & Chi-square & Df & Sig. \\
\hline \multirow{3}{*}{ Step 1 } & Step & 236350,037 & 6 &, 000 \\
\cline { 2 - 5 } & Block & 236350,037 & 6 &, 000 \\
\cline { 2 - 5 } & Model & 236350,037 & 6 &, 000 \\
\hline
\end{tabular}

Hasil uji pengaruh variabel bebas secara simultan dapat dilihat pada Tabel 2, yaitu Omnibus test of model coefficients. Berdasarkan hasil tes tersebut menunjukkan nilai signifikansi model $0,000<\alpha=0,05$, maka pada tingkat signifikansi $5 \%$ kita dapatmenolak $H 0$. Dengan hasil tersebut, dapat disimpulkan bahwa secara simultan atau minimal satu variabel bebas berpengaruh terhadap variabel tak bebas. Selanjutnya berapa besar pengaruhnya dapat dilihat pada koefisien determinasi $(R 2)$, yang berarti besarnya sumbangan/pengaruh variabel bebas terhadap variabel tak bebas.

Tabel 3. Model Summary

\begin{tabular}{cccc}
\hline Step & $\begin{array}{c}-2 \text { Log } \\
\text { likelihood }\end{array}$ & $\begin{array}{c}\text { Cox \& Snell } \boldsymbol{R} \\
\text { Square }\end{array}$ & $\begin{array}{c}\text { Nagelkerke } \boldsymbol{R} \\
\text { Square }\end{array}$ \\
\hline 1 & $1315751,992^{\mathrm{a}}$ &, 050 &, 175 \\
\hline
\end{tabular}

Pada Tabel 3 nilai koefisien determinasi (Nagelkerke $R$ Square) sebesar 0,175 . Hal ini berarti bahwa variabel dependen mampu dijelaskan oleh variabel independen sebesar $17,5 \%$, dan sisanya sebesar $82,5 \%$ dijelaskan faktor lain yang tidak terdapat pada model.

Tabel 4. Variables in The Equation

\begin{tabular}{rlrrrrrr}
\hline & & $\boldsymbol{B}$ & \multicolumn{1}{c}{$\boldsymbol{S . E .}$} & \multicolumn{1}{c}{ Wald } & $\boldsymbol{d f}$ & \multicolumn{1}{c}{ Sig. } & $\operatorname{Exp(B)}$ \\
\hline Step 1a & Edu &, 902 &, 007 & 18415,482 & 1 &, 000 & 2,464 \\
\cline { 2 - 8 } & Smart & 1,577 &, 007 & 52094,387 & 1 &, 000 & 4,838 \\
\cline { 2 - 7 } & Hs &, 384 &, 005 & 5314,183 & 1 &, 000 & 1,468 \\
\cline { 2 - 7 } Work & $-2,377$ &, 006 & 144693,844 & 1 &, 000 &, 093 \\
\cline { 2 - 7 } & Pov &, 296 &, 006 & 2644,492 & 1 &, 000 & 1,345 \\
\cline { 2 - 7 } & City &, 401 &, 006 & 4280,537 & 1 &, 000 & 1,493 \\
\cline { 2 - 7 } & Constant & $-3,496$ &, 011 & 92684,836 & 1 &, 000 &, 030 \\
\hline
\end{tabular}


Pada Tabel 4 dapat dilihat besar dan arah pengaruh variabel-variabel yang mempengaruhi anak putus sekolah secara signifikan pada taraf uji $\alpha 5 \%$. Variabelvariabel tersebut adalah pendidikan kepala rumah tangga (edu), kepemilikan KIP/PIP (smart), jumlah art (hs), aktivitas bekerja (work), kemiskinan (pov), dan daerah tempat tinggal (city). Sehingga model persamaannya adalah sebagai berikut:

$$
P(y=1 \mid x)=\frac{e^{-3,496+0,902 e d u+1,577 \text { smart }+0,384 h s-2,377 \text { work }+0,296 \text { ov }+0,401 \text { city }}}{1+e^{-3,496+0,902 \text { edu }+1,577 \text { smart }+0,384 h s-2,377 \text { work }+0,296 \text { ov }+0,401 \text { city }}}
$$

\section{Interpretasi}

Interpretasi dari model persamaan regresi logistik yang dihasilkan akan diuraikan di bawah ini.

1. Odds ratio (perbandingan resiko)

Besarnya pengaruh variabel independen terhadap variabel dependen dapat dilihat dengan nilai Exp $(B)$ atau sering juga disebut Odds Ratio (Santika, 2020). Tingkat pendidikan kepala rumah tangga berpengaruh signifikan terhadap anak putus sekolah. Nilai Exp (B) atau odds ratio sebesar 2,464 menunjukkan bahwa kecenderungan anak putus sekolah dengan pendidikan krt SMP ke bawah 2,464 kali dibandingkan dengan krt berpendidikan SMA ke atas. Hasil tersebut dapat juga diartikan semakin tinggi tingkat pendidikan krt akan semakin tinggi tingkat partisipasi sekolah anak. Hal ini dapat dimaklumi karena tingkat pendidikan dapat membuat pola pikir dan persepsi yang semakin maju dan akan mendorong anak agar menempuh pendidikan lebih tinggi. Demikian juga halnya dengan anak, akan semakin termotivasi. Hasil penelitian tersebut sejalan dengan penelitian yang dilakukan oleh Asmara \& Sukadana (2017) dan Astari P \& Mujiati (2013) bahwa pendidikan yang ditamatkan orang tua berpengaruh terhadap tingkat putus sekolah anak. Semakin rendah pendidikan orang tua, akan semakin tinggi kemungkinan anak untuk berhenti sekolah. Pendidikan orang tua yang rendah bisa saja mempunyai motivasi yang rendah pula dalam pendidikan anak.

Program pemerintah berupa Kartu/Program Indonesia Pintar sangat bemengaruh positif untuk menekan angka putus sekolah pada anak usia 7-18 tahun. Dari Tabel 4 dapat dilihat kecenderungan anak yang tidak memiliki/ mendapat KIP/PIP 4,838 kali untuk pusus sekolah dibanding dengan anak yang mendapatkan KIP/PIP tersebut. Hal ini menunjukkan bahwa bantuan pemerintah di bidang pendidikan sangat dibutuhkan untuk meningkatkan partisipasi sekolah. Bantuan berupa KIP/PIP dapat memberikan kesempatan kepada masyarakat untuk menikmati pendidikan yang lebih baik, agar program wajib belajar 12 tahun dapat tercapai. Hasanah dan Safruddin Jabar (2017) dalam penelitiannya yang berjudul "Evaluasi Program Wajib Belajar 12 Tahun Pemerintah Daerah Kota Yogyakarta", menyatakan bahwa subsidi yang tidak tepat merupakan salah satu faktor penghambat program wajib belajar 12 tahun.

Berikutnya adalah jumlah anggota rumah tangga yang juga merupakan variabel yang mempengaruhi anak putus sekolah. Semakin besar jumlah anggota rumah tangga akan semakin berat beban yang harus ditanggung. Dalam penelitian ini, anak usia 7-18 tahun yang tinggal bersama keluarganya dengan jumlah art 6 
orang atau lebih memunyai kecenderungan 1,468 kali putus sekolah dibanding dengan jumlah art 5 orang ke bawah. Hal ini sejalan dengan hasil penelitian yang dilakukan Arsitin (2015) yang menyimpulkan bahwa jumlah tanggungan keluarga beppengaruh terhadap anak putus sekolah. Jika jumlah anggota/tanggungan lebih banyak akan mempengaruhi kualitas anak, karena harus memenuhi kebutuhan yang lebih besar. Berbeda dengan penelitian yang dilakukan Asmara \& Sukadana (2017), menyatakan bahwa jumlah anggota keluarga berpengaruh negatif terhadap keputusan anak untuk tidak sekolah lagi atau berhenti sekolah namun pengaruhnya tidak signifikan. Hal ini dimungkinkan dengan keterbatasan jumlah dan kondisi sampel yang diteliti, dimana unit penelitiannya adalah siswa pada lima sekolah tingkat SLTA di Kabupaten Buleleng dengan jumlah sampel 101 siswa yang putus sekolah maupun tidak.

Aktivitas bekerja seorang anak juga berpengaruh terhadap angka putus sekolah. Anak yang bekerja akan terganggu kegiatan sekolahnya, terlebih anak yang bekerja diajak orang tuanya untuk membantu meringankan beban ekonomi yang harus ditanggung dalam keluarga. Nilai odds ratio pada Tabel 4 menunjukkan bahwa anak usia 7-18 tahun yang tidak bekerja mempunyai kecenderungan lebih kecil untuk putus sekolah dibandingkan dengan anak yang bekerja yaitu sebesar 0,093 kali. Hasil ini sejalan dengan penelitian yang dilakukan oleh Malik dan Sumarno (2016) yang menyatakan bahwa salah satu penyebab anak enggan bersekolah dan akhirnya tidak sekolah lagi adalah bekerja walaupun hanya sekedar membantu meringankan beban ekonomi keluarga.

Variabel selajutnya adalah kemiskinan rumah tangga. Biasanya kemiskinan dikaitkan dengan kemampuan ekonomi yang lemah atau pendapatan yang kurang memadai. Konsep kemiskinan dalam penelitian ini menggunakan konsep yang dipakai BPS, yaitu konsep apakah rumah tangga mampu memenuhi kebutuhan yang sangat mendasar. Pada Tabel 4 dapat dilihat bahwa kecenderungan anak yang tinggal bersama keluarganya yang miskin akan putus sekolah 1,345 kali dibandingkan dengan yang tidak miskin. Beberapa penelian yang telah dilakukan menyimpulkan hal yang sama, di antaranyahasil kajian tentang faktor penyebab anak putus sekolah yang dilakukan olehTitik Kamsihyati et al. (2016) menyatakan bahwa faktor ekonomi merupakan salah satu faktor penyebab anak putus sekolah, karena tidak mampu menyediakan keperluan dan kelengkapan belajar. Begitu juga dengan Mujiati et al. (2018) dalam penelitiannya menyimpulkan bahwa faktor ekonomi keluarga yang lemah dapat menyebabkan siswa putus sekolah, karena tidak mampu membiayai sekolah.

Selanjutnya adalah variabel daerah tempat tinggal, dimana pada penelitian ini yang dimaksud adalah daerah perkotaan dan perdesaan. Kategori ini berdasarkan tingkat kemajuan pembangunan suatu desa dan fasilitas umum yang dimilikinya. Kecenderungan untuk putus sekolah padaanak usia 7-18 tahun yang tinggal di daerah perdesaan lebih besar 1,493 kali dibandingkan dengan yang tinggal di daerah perkotaan. Hal ini dimungkinkan karena kemudahan akses dan fasilitas sekolah di daerah perkotaan lebih memadai. Asmara dan Sukadana (2017) dalam penelitiannya menyatakan bahwa faktor kemudahan akses dalam hal ini didekati dengan jarak antara rumah dan sekolah dapat mempangaruhi minat anak bersekolah, sehingga cenderung putus atau berhenti sekolah. Kamsihyati et al 
(2016) dalam penelitiannya menyimpulkan bahwa lingkungan tempat tinggal dimana banyak orang berpendidikan rendah merupakan salah satu faktor yang mempengaruhi anak putus sekolah, karena faktor lingkungan seperti itu tidak mendukung anak untuk tetap bersekolah sekolah dan biasanya ini terjadi di daerah perdesaan.

1. Adjusted probability (probabilitas terjadi) suatu peristiwa $y=1$ dengan karakteristik diketahui.

Model regresi logistik yang dihasilkan berdasarkan Tabel 4 adalah sebagai berikut:

$$
P(y=1 \mid x)=\frac{e^{-3,496+0,902 e d u+1,577 \text { smart }+0,384 h s-2,377 \text { work }+0,296 \text { pov }+0,401 \text { city }}}{1+e^{-3,496+0,902 \text { edu }+1,577 \text { smart }+0,384 h s-2,377 \text { work }+0,296 \text { pov }+0,401 \text { city }}}
$$

Persamaan tersebut dapat memberikan prediksi probabilitas anak putus sekolah dengan karakteristik tertentu. Misalkan karakteristiknya adalah pendidikan kepala rumah tangga SMP, anak tidak memiliki/mendapatkan KIP/PIP, jumlah anggota rumah tangga 6 orang, aktivitas anak bekerja, rumah tangga mereka miskin, dan tinggal di daerah perdesaan, maka probabilita anak tersebut putus sekolah adalah sebesar 51,60 persen. Jika pada kondisi sebaliknya, yaitu pendidikan kepala rumah tangga SMA atau kebih tinggi, anak memiliki KIP/PIP, jumlah anggota rumah tangga 4 orang, anak tidak bekerja sehingga dapat berkonsentrasi sekolah, rumah tangga mereka tidak miskin, dan tinggal di daerah perkotaan, maka probabilitas anak tersebut putus sekolah adalah sebesar 8,49 persen. Beberapa kondisi dapat disimulasikan menggunakan model tersebut.

\section{KESIMPULAN}

Berdasarkan pembahasan di atas, diperoleh kesimpulan bahwa enam variabel yang diteliti berpengaruh nyata terhadap anak putus sekolah dengan tingkat signifikansi $\alpha=0,05$. Variabel tersebut adalah pendidikan kepala rumah tangga, kepemilikan Kartu/Program lindonesia Pintar, jumlah anggota rumah tangga, aktivitas anak yang bekerja, anak yang tinggal di rumah tangga miskin, dan daerah tempat tinggal yaitu daerah perkotaan dan perdesaan. Variabel yang paling dominan dengan nilai odds ratio sebesar 4,838 adalah kepemilikan Kartu/Program Indonesia Pintar (KIP/PIP). Artinya anak yang tidak memiliki/mendapat KIP/PIP mempunyai kecenderungan untuk putus sekolah sebesar 4,838 kali dibandingkan dengan anak yang memiliki/mendapat KIP/PIP. Persamaan regresi logistik yang dihasilkan dalam penelitian ini, dapat digunakan untuk memprediksi probalitas anak putus sekolah dengan kondisi tertentu.

Dari hasil temuan tersebut, diharapkan pemerintah dapat menyalurkan dan menambah anggaran KIP/PIP untuk masyarakat yang membutuhkan agar angka putus sekolah dapat ditekan. Masyarakat juga diharapkan dapat mendukung program hak belajar 12 tahun. 


\section{REFERENSI}

Arsitin, N. F. (2015). Faktor-faktor yang berpengaruh terhadap anak putus sekolah tingkat Sekolah Menengah Pertama (SMP) di Kecamatan Bondowoso. Jurnal Pendidikan Geografi, 1(2017), 513-515. https://doi.org/10.1136/ bmj.2.2017.513.

Asmara, Y., \& Sukadana, I. (2017). Mengapa angka putus sekolah masih tinggi? (Studi Kasus Kabupaten Buleleng Bali). E-Jurnal Ekonomi Pembangunan Universitas Udayana, Vol. 5(12), 1347-1383.

Astari, G. A. R., Srinadi, I. G. A. M., \&Susilawati, M. (2013). Pemodelan jumlah anak putus sekolah di Provinsi Bali dengan pendekatan semi-parametric geographically weighted poisson regression. E-Jurnal Matematika, Vol. 2(3), 29. https://doi.org/10.24843/mtk.2013.v02.i03.p045.

Badan Pusat Statistik Indonesia. (2019). Indikator kesejahteraan rakyat 2019: Infrastructure development in Indonesia. 270. https://doi.org/4102004.

Cahyani, N. K. A. S., Suciptawati, N. L. P., \&Sukarsa, K. G. (2019). Identifikasi faktor yang memengaruhi anak putus sekolah di Kabupaten Badung. $E$ Jurnal Matematika, Vol. 8(4), 289. https://doi.org/10.24843/mtk.2019. v08.i04.p267.

Hasanah, Y. M., \&Safruddin. (2017). Evaluasi program wajib belajar 12 tahun pemerintah daerah Kota Yogyakarta. Jurnal Akuntabilitas Manajemen Pendidikan, Vol. 5(2), 228-239.

Iman Gani \& Siti Amalia.(2015). Alat analisis data: Aplikasi statistik untuk penelitian bidang ekonomi dan sosial (Revisi). Andi.

Kamsihyati, Titik, Sutomo, S. F. (2016). Kajian faktor-faktor penyebab anak putus sekolah di Desa Jangrana Kecamatan Kesugihan Kabupaten Cilacap. Geo Edukasi, Vol. 5(1), 16-21.

Malik, H. K., \& Sumarno, S.(2016). Kepedulian orang tua terhadap pendidikan anak untuk menyelesaikan program wajar 9 tahun. Jurnal Pendidikan Dan Pemberdayaan Masyarakat, Vol. 3(1), 38. https://doi.org/10.21831/jppm. $\mathrm{v} 3 \mathrm{i} 1.8061$.

Mujiati, M., Nasir, N., \& Ashari, A. (2018). Faktor-faktor penyebab siswa putus sekolah. Didaktis: Jurnal Pendidikan Dan IImu Pengetahuan, Vol. 18(3), 271-281. https://doi.org/10.30651/didaktis.v18i3.1870.

Saepuloh, D., \& Suherman, A. (2018). Analisis penyebab angka putus sekolah Kota Tangerang. Jurnal Penelitian Dan Karya IImiah, Vol. 2(XVIII), 98-111.

Santika. (2020). Faktor-faktor yang mempengaruhi prestasi akademik mahasiswa. Jurnal Pendidikan, Vol. 21(1), 1-17. https://doi.org/10.33830/jp.v21i1. 704.2020.

Wassahua, S. (2016). Analisis faktor-faktor penyebab anak putus sekolahdi Kampung Wara Negeri Hative Kecil Kota Ambon. Al - Iltizam, Vol. 1(2), 93113. https://jurnal.iainambon.ac.id/index.php/ALT/article/view/199. 